\title{
The methodology of Paul Willis. A review of "Learning to Labor: How Working Class Kids get Working Class Jobs"
}

\author{
Anders Vedel Hadberg \\ Universidad de Copenhaguen \\ andershadberg@stud.ku.dk
}

\begin{abstract}
This article explores some basic features of the methodology used by Paul E. Willis in his great work "Learning to Labour" from 1976. Through a backward approximation from the presentational form the article tries to comprehend the consistency of Willis' analytical and conceptual apparatus applied in his research process. This is done partly on basis of the explication of the concept self, and the special explanatory typology in which this concept is employed, and partly through the two concepts penetration and limitation.
\end{abstract}

The conclusion at which this article arrives is that Willis' investigation is a development of the Marxian principles of dialectics in a cultural setting.
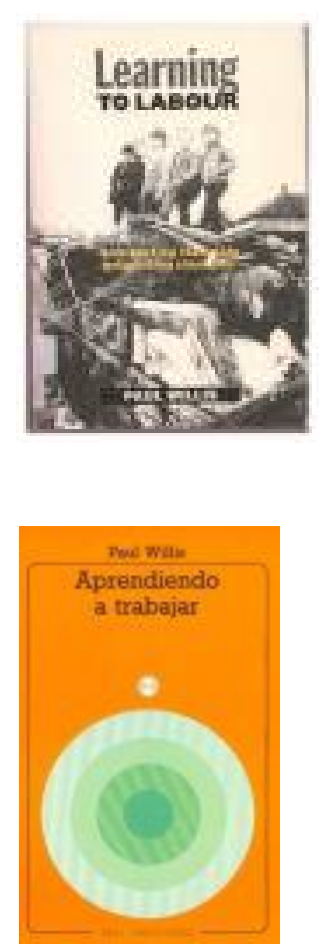

Willis, Paul E. (1977) Learning to labour: how working class kids get working class jobs. Aldershot: Coger. ISBN: 0-566-00150-0

Willis, Paul E. (1977) Aprendiendo a trabajar. Madrid: Akal. 1988. ISBN: 847600-296-3 


\section{Introduction}

Paul Willis (1976) has made an excellent attempt to not only describe but also explain why the reproduction of the working class as subsumed under capital continues to exist from a social psychological point of view. Through this perspective he examines the various aspects of cultural development among young school boys in an English industrial city and reaches some remarkable conclusions as to how this culture reinforces or in fact reifies the working class as subordinate to laws of capitalism.

The interesting aspect of Willis' work that remains to be explicated is, however, the methodology, i.e. the method of investigation. Willis writes in his foreword that he has spent 3 years studying 12 boys through their last two years of school and the first year of employment - the last year even worked alongside these boys in the work shop ${ }^{1}$. But despite this great effort no real attempt has been made on his side to make explicit his method of research. It will be the task for this essay to explicate some features of the method of Willis.

\section{Presentational form.}

The first aspect to be considered is the form in which Willis presents the analysis of this cultural study - a form we shall call the presentational form. It is the thought here that we through a reciprocal movement from explication of presentational form back to the research process will be able to comprehend the method that has led Willis to encounter these - at the time - breaking results.

As an initiating observation we can note that the book is divided into two distinct sections, each with a different way of projecting the culture of the boys and the institutional environment that surrounds them: the county school.

The first section is an ethnographic depiction of the boys, their habits and cultural opposition to school. The second half of the book is an analytic reconstruction of the dynamics of the cultural development, reinforcement and determination which the counter-school culture undergoes viewed in a purely analytical manner.

\section{Thick description and validation.}

The ethnographic description means "thick descriptions" ${ }^{2}$ of the environment in which the boys act but also of the specific cultural elements of what Willis calls the counter-school culture (CSC). The CSC is

\footnotetext{
${ }^{1}$ Willis (1976): p. 4-6
}

${ }^{2}$ As a methodological concept this provides of course credibility and validity to the work. For conceptual clarification see Bryman (2004). 
a counter force to the existing power structure of the school, a structure which Willis denotes the "Basic Teaching Paradigm" (BTP). ${ }^{3}$ We will return to the relationship between the two forces later on.

The counter-school culture expresses itself through various elements which are shown by an extensive use of quotations from the many interviews Willis has conducted. This obviously brings an element of validity to his work as it clearly specifies how the conclusions made by Willis originate from the actions and the words of the subjects (or objects one might say) of his research.

The thick description and quotations do not only function as severe documentation, but also make it possible to follow Willis in his way from empery to the theorization of these results. As the concepts to describe the cultural expressions and forms are held directly against the material we see them reflected back in a process of validation. In this way he opens the research process: by projecting both the essential parts of the material, the object of our perception, and the key to understand this material.

As mentioned above this rests upon the epistemological features of Marxist theory of perception, in which the reality is coercive but at the same time it does not present itself as it is structured "in itself" but rather in a subverted form of itself as it appears for the subjects of perception. Therefore the social researcher must critically examine this reality to uncover the structures that work upon social reality coercively. This is exactly what Willis intends and succeeds in doing here. ${ }^{4}$

\section{Advances.}

There are here two major advances by this methodological recomposition or representation of his material, which must be made clear: first it corresponds to the ontological and epistemological tradition in which Willis voluntarily inscribes: the Marxist (and hence materialist) conception of reality - that leads to the second: an emphasis on the necessity of investigating both words and action of the boys' culture. Let us look upon these advances or points of orientation that are constructed in Willis' presentation.

The first point developed is that of correspondence with the Marxist theory of society which Willis declares his relationship to at the beginning of his work. This correspondence is manifest through the presentational form i.e. the extensive use of quotations. The central thought of Marxist scientificphilosophical point of view is exactly that the valuated structure of reality emerges from reality itself as a coercive or - in the analysis of empery - as a certain configuration of this materiality ${ }^{5}$. This

${ }^{3}$ The different elements of the two cultures will not be dealt with in their individual parts; the focus rests solely upon the methodology. See illustrations of both cultural structures in sheet A\&B.

${ }^{4}$ The ontological division between the object as it exists "in itself" and the perception of the humans, the "for itself", can never melt together completely - as the appearance of the structure or essence of an instance will never equal the structure itself according to the dialectical way of thought, Kirkeby (1975), Carchedi (1987).

${ }^{5}$ See Kierkeby (1975), Zeleny (1980) 
establishes a dimension of coherence, an internal validity, as this presentation corresponds to the epistemological theory of Marxism.

Secondly the investigation of counter-school culture includes a very important point: the notion of culture as being both language and action. There exists, it seems, a dialectical relationship between these expressive forms of the culture where the physical appearance or performance of the boys on the one hand seems to reflect elements of the culture but on the other also generates and contradicts some of the elements expressed verbally ${ }^{6}$.

The necessity of investigating both language and action becomes very important in Willis' critique of other attempts to comprehend development of class consciousness; because one is simply not able to understand the dynamics of the culture only by interviewing or questionnaires ${ }^{7}$. This is in fact some of the features that lead him to understand how certain limitations of the boys' oppositional culture appear as reproduction or inability to penetrate the determination of the school. ${ }^{8}$

\section{Three dimensions of ontological analysis.}

Each of the two chapters of the analysis rests upon a three dimensional investigation of reality, starting from the most concrete and moving to the abstract. This is also the case between the two chapters; the first being very descriptive the second dealing with the cultural forms in a purely analytical manner. The three layers of the analysis which obviously constitutes reality are 1) the boys and their clique in the class room situation 2) the institutional settings, the field of oppositional forces (including state apparatus and parents) and 3) the abstract and physical structures of society moving behind the two forces in the school: class culture, ideology and economic structures.

In some way Willis' analysis is very similar to Bourdieu's concept of "the field" in the sense that certain dynamics work in a semiautonomous fashion within different institutional settings in society. The struggle for superiority as the main core of the field, with the actors trying to enforce their own system of value, has a great similarity to Bourdieu's work. ${ }^{9}$

The major difference seems Willis' attempt to see the interrelation between the different layers of reality much clearer and to provide an explanation of cultural phenomenon which builds on clarification

\footnotetext{
${ }^{6}$ An outstanding example is the contradiction between the way boys behave when chasing "easy lays" in the pubs and their verbally expressed notion of women in connection to family life, i.e. wives/girlfriends, Willis (1976) p. 43-47 and explicitly in the chapter "notes towards a theory of cultural forms and social reproduction".

${ }^{7}$ See Willis (1976) p. $171-178$

${ }^{8}$ The contradictions within the language and between language and (body) action are fertile for the growth of sexism and patriarchy.

${ }^{9}$ See the three dimensional structure of Willis analysis in the additive illustration C.
} 
of the complex interaction of these layers. In essence he holds the imperative that the explanation of the concrete must be explained by a dynamical relation to the abstract and vice versa ${ }^{10}$.

Let us now turn to these layers of reality and specify how Willis incorporates them in his research process.

\section{The research process.}

From the above it seems clear, that the research process of Willis must be understood as an attempt to analyze the real movement of the counter-school culture. More thoroughly we shall investigate how he explains and reconstructs the movements of the counter-school culture in order to comprehend the reproduction of the working class. Here it will be clear exactly how we should understand the research of Willis; namely as a reinterpretation of the Marxist dialectics in a cultural context.

\section{By way of ethnography.}

In the ethnography Willis uses two complementary concepts to explain the movement of power and opposition - the struggle for superiority: differentiation and integration. These characterize the process in which the BTP creates differentiation within the school causing CSC's of various types to arise. This process is specific in terms of which power resources the two struggling forces are drawing upon in the field of action. In this way the conceptual couple enables Willis to point out: a) how is the struggle differentiating and integrating CSC in the institutional setting of the school b) the characterization of potential and actual resources mobilized from different layers of the societal structure.

The emphasis is exactly at the movement, the processional character of differentiation, opposition, and reintegration, containment of opposition. In this way the ethnography enables him to describe a process and its constitutive elements as they appear for the participant watcher - the basic feature of his study. The descriptions can therefore not explain or explore the relations between the significant levels of interaction - nor can it determine their status in contradictory struggle between the central power, BTP, and its opposition CSC. The ethnography however is merely a descriptive analysis. The real movement must according to Willis be understood in the analytical section of his work. $^{11}$

In this sense there is a cleavage between the participant watcher and the researcher. The ethnography is, not entirely, but most of all a collection of data. The real research begins when analyzing the collected data. But by projecting both processes: the collection and analysis of data it enables the viewer to follow and validate his conclusion.

We will now turn to the section of analysis to explore what he advances here to understand the way of his research process.

\footnotetext{
${ }^{10}$ A simple look at the table of "contents" reveals this composition, which is also introduced in the "introduction". Willis p. v-vi + p. 1-7.

${ }^{11}$ Willis, p. 120.
} 


\section{Limitations and penetrations.}

The two all important concepts which Willis develops in his analytical process are penetration and limitation. With the axis of these two concepts Willis interprets and reconstructs the real movement of the development of the cultural elements of the CSC.

Penetration is meant to designate impulses within a cultural form towards the penetration of the conditions of existence of its members and their position in the social whole but in a way that is not centered, essentialist or individualist.

Limitation is meant to designate those blocks diversions and ideological effects which confuse and impede the full development an expression of these impulses. ${ }^{12}$

From this definition the term partial penetration arises as concept of how these two matters come together in the concrete field explored by the ethnography.

Penetration is understood as being without independence and bound partially to the object it tries to penetrate. Limitation is understood as both internal and external cultural elements working against the penetration.

In this sense the reproduction of cultural elements is not a question of mere outside determination, but a matter of creativity, a collective directed will, within a group of actors themselves overlapping and positioning before finally taking over the outside determination. ${ }^{13}$

Penetration as an analytical concept does then explore the more or less conscious movement of the subject(s) through the projections of the institutional setting (the conditions of existence) and behind to see the real function of the system. It thus explains the cognitive development of the subject as penetrating the different layers of reality uncovering the real connection of reality's determining instances. ${ }^{14}$

Limitation as a concept has its similarity with the Althusserian concept of interpelation adopted by Butler used to characterize a process in which the subject expresses a (sexual) position determined by the hegemony power, which the subject conceives of as having an internal reference. This however is just an adjustment to the demands of the exercising power. ${ }^{15}$

In this tradition the internal structure of the self is by all means constructed. This means that we cannot find an identity in the existing hegemony that corresponds to the self in terms of natural feelings or desires. These are instead naturalized by power. In this sense there is nothing underneath language - the proclamation of identity. ${ }^{16}$

${ }^{12}$ Willis, p. 119.

${ }^{13}$ Willis, p. 120.

${ }^{14}$ It is the clear point of Willis that the boys' uncovering of the real functioning of the BTP is central to their identity.

${ }^{15}$ Córdoba(2003)

${ }^{16}$ Ibid. 
However this does not seem to be the case for Willis. Speaking of the dialectics of self ${ }^{17}$ - without explicitly defining it though - he urges us to understand his perspective upon the self as being somewhat different than the Althusserian conception.

To fully understand what is at stake here we must turn to first the formulation of self and since to the rearticulation of the principles of dialectics that stems from this analysis.

For instance let us stop with the formulation about the CSC culture:

In the violence there is the fullest if unspecified commitment to a blind or distorted form of revolt. It breaks the conventional tyranny of 'the rule'. It opposes it with machismo. It is the ultimate way of breaking the flow of meanings which are unsatisfactory, imposed from above, or limited by circumstances. It is the one way to make the mundane suddenly matter. The usual assumption of the flow of the self from the past to the present is stopped: the dialectics of time is broken. Fights, as accidents and crisis, strand you painfully in 'the now'. Boredom and petty detail disappear. It really does matter how the next seconds pass. And once experienced, the fear of the fight and the ensuing high as the self safely resumes its journey are addictive. (Willis, p.34)

Here we see that the self is a continuous creation constituted by the actions taken and responses made to experiences in a way that melts actions and responses together. Experience and response are linked together in a movement that in a certain way constructs the identity as a real existing totality of the experiences of the self.

This means that identity is not a choice - a statement - independent of context and internal reference - that can be changed situationally. Any sudden change has to refer to the prior instance experienced by the subject in which the possibility of change was born. This means that the prior moments experienced of some parts stay as an inherent part of the identity.

This does not implicate that the development of the self is constant. It can experience an instantaneous discontinuity. We see the fight as a brake-up of the dialectics of self - an instance in which the fundamental character of the situation is penetrated - or in Marx' terms superseded. ${ }^{18}$

This tells us that there exist instances in which the determined development of the subject by institutionalized power has the potential to be superseded.

The self can free itself from this determinacy and create a new and real meaning that refers to a state within the subject. Thereby the concept of identity becomes a struggle for the freedom to be able to act out the desires that even though they appear as 'unspecified commitments' they have a reference to reality existing within the subject and their realization does in fact point to a real supersession of the suppressing instance.

Supersession terms exactly this point of Willis, that the process of development is a process within which the overcoming of one situation leads to a fundamental new situation - but with some of the old

\footnotetext{
${ }^{17}$ Willis p.34

${ }^{18}$ Carchedi (1987)
} 
inherent in it. The old has changed is character fundamentally and therefore resides in the new as something determinate. This is the case with the inversion of the formal values that continuously occurs within the informal group, CSC.

Here the values impeded upon the boys are overcome (partially) and inverted into something new. Yet the old values are the conditions of this supersession and remain as part of the informal, but they do so in a fundamental new character. Therefore the informal group of CSC always refers to the values of the formal.

\section{Willis and the principles of dialectics.}

After having articulated these research principles of the dialectics of self by Willis, let us now turn to how they appear in the terms of limitation and penetration. Seeing the two concepts in the light of the self we can understand these as a conceptual development of the principles of dialectics in the research process of Willis - as he has inherited them from Marx. ${ }^{19}$

In the Marxian terms reality exist as a unity of instances that cannot exist with out each other (unity) and which must exist either by trying to supersede each other (in contradiction) or by trying to reproduce each other (in correspondence). In other words reality is seen as a complex structure of relations some which try to reproduce themselves, others try to supersede themselves. A dialectical instance is thus a unity of two instances in which there exists correspondence and contradiction; meaning that one instance needs to determinate the other in order to reproduce itself. The other instance attempts on the other hand to supersede itself thereby superseding the instance as a unity

To gain knowledge of their potentials each instance of a unity must interact with each other. This continues in a process of unity, correspondence and contradiction with supersessions and reproductions of instances. ${ }^{20}$

It seems clear now that the supersession of a given instance in which there exists determination is by Willis set in a cultural definition as penetration. Penetration means in this case that the determinacy attempted by the school through the BTP can be superseded by the CSC - it has the potential. Is does so only partially; meaning that the form of the CSC changes but not its fundamental character as reproductive for the capitalist dominion of the working class. Limitation on the other hand characterizes the elements of the culture which are not superseded but are determined by the BTP causing CSC to remain a function of capitalist reproduction.

The struggle for superiority thus represents a unity of instances and constitutes a dialectical relationship. It does so in the sense that the one instance BTP is trying to determine the other CSC using it to reproduce itself. Therefore CSC may change its form but not its fundamental character when/if determined by BTP. On the other hand CSC attempts to supersede itself causing a supersession of the instance as a whole.

\footnotetext{
${ }^{19}$ The Marxian conception is based upon Zeleny (1980 [1986]), and Carchedi (1987)

${ }^{20}$ Carchedi (1987) p. 74-78, Zeleny (1980): p. 74.
} 
The instance being the unity of BTP and CSC is of course the school exercising its functional role as reproduction of the working class in a form that is that reproduces capital. This is the attempt of the working class to supersede the position of domination under capital by penetrating the elements of cultural determinacy within its state institutions.

\section{Beginning again}

Concluding our tour here, we can say, that the 'methodological' work of Paul Willis is an extensive reformulation of the Marxist paradigm within the field of socio-psychological research. He re-actualizes the paradigm in a modern setting that enables him to understand the problematic of reproduction of societal classes.

It becomes clear how the conceptual development of Willis on the basis of the principles of dialectics, originating from the Marxian works, structures his research process and follows his aim: to investigate the fundamental class structures as they affect the concrete appearance in the culture of working class boys and reproduces by their actions.

The results stemming from this analysis must therefore be attributed to the features of the methodological investigation outlined above and can only be understood in this context. A reproduction of his work must therefore also be based upon these principles.

One must of course ask the question whether the answers gained by Willis' investigation have sufficiently solved the problem of how the working class can free itself from the capitalist oppression through the investigation of its fallacies. If not, the reformulation of the Marxian dialectics must be reattempted (or rejected) - and the research must eventually begin again.

\section{Bibliography}

Carchedi, Guglielmo(1987): Class analysis and social research,

Córdoba García, D. (2003): Identidad sexual y performatividad. Athenea Digital, 4.. Disponible en http://antalya.uab.es/athenea/num4/cordoba.pdf

Kierkeby, Ole Fogh (1975): Kapitallogik og historie: bidrag til en fagkritik, Roskilde: RUCs Forlag.

Zeleny, Jindrich (1980)[1968]: The Logic of Marx. Oxford Blackwell.

Bryman, Alan (2004): Social Research Methods. Oxford: Oxford University Press.

Willis, Paul E. (1976): Learning to labour. How working class kids get working class jobs. Aldershot (UK): Gower.

Lecourt, Dominique (1975): Lenin og den filosofiske kamp. Copenhagen: Rhodos. 


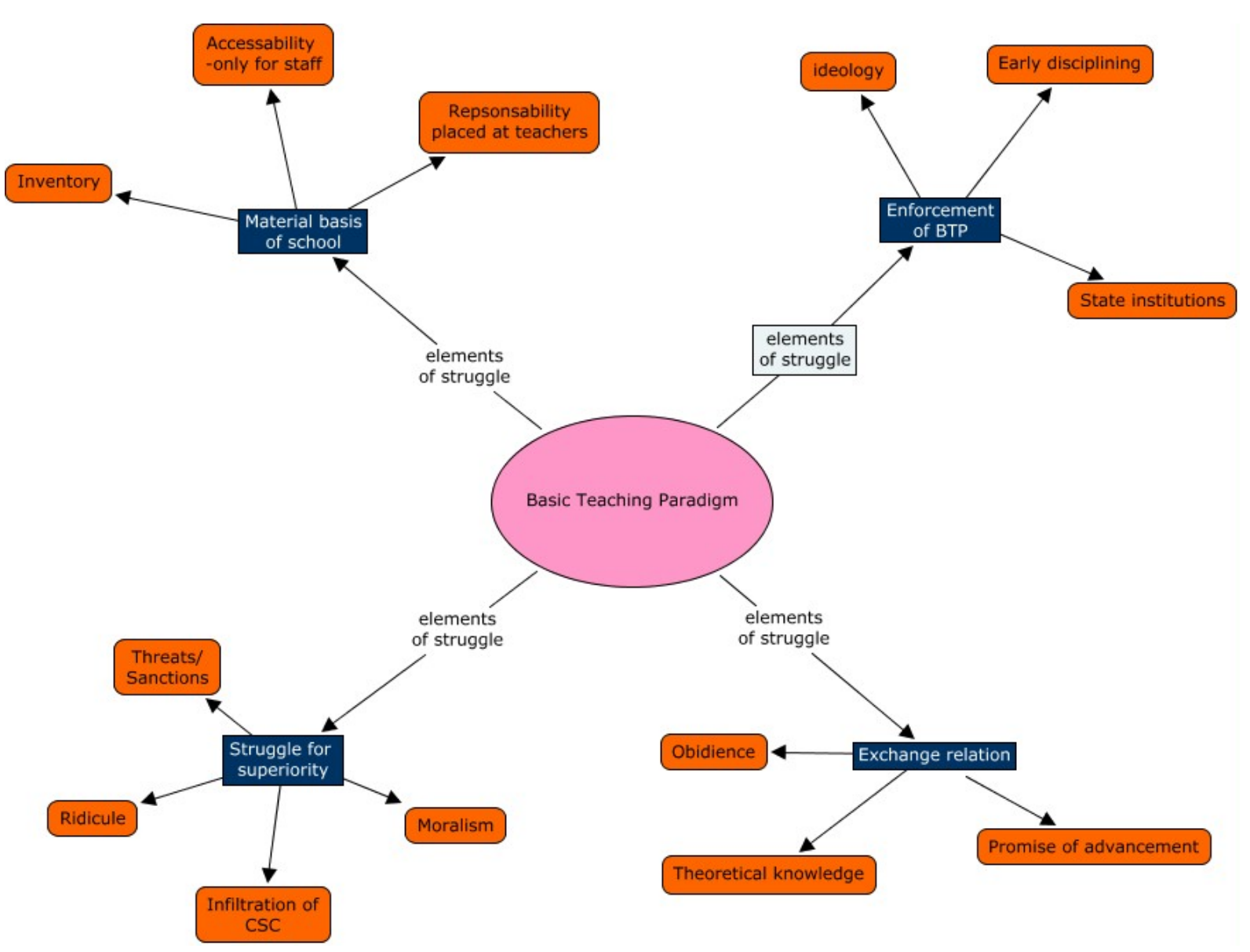




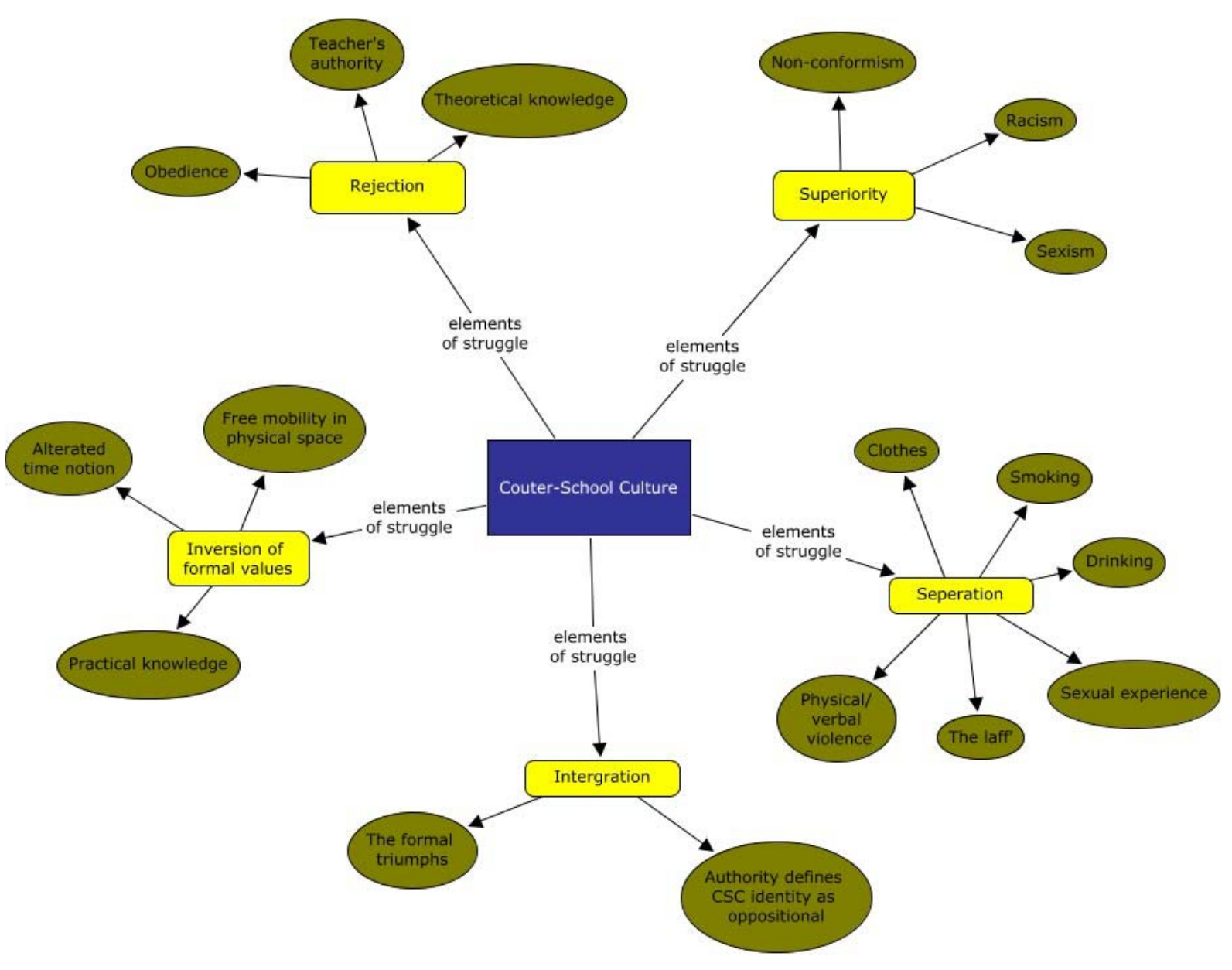




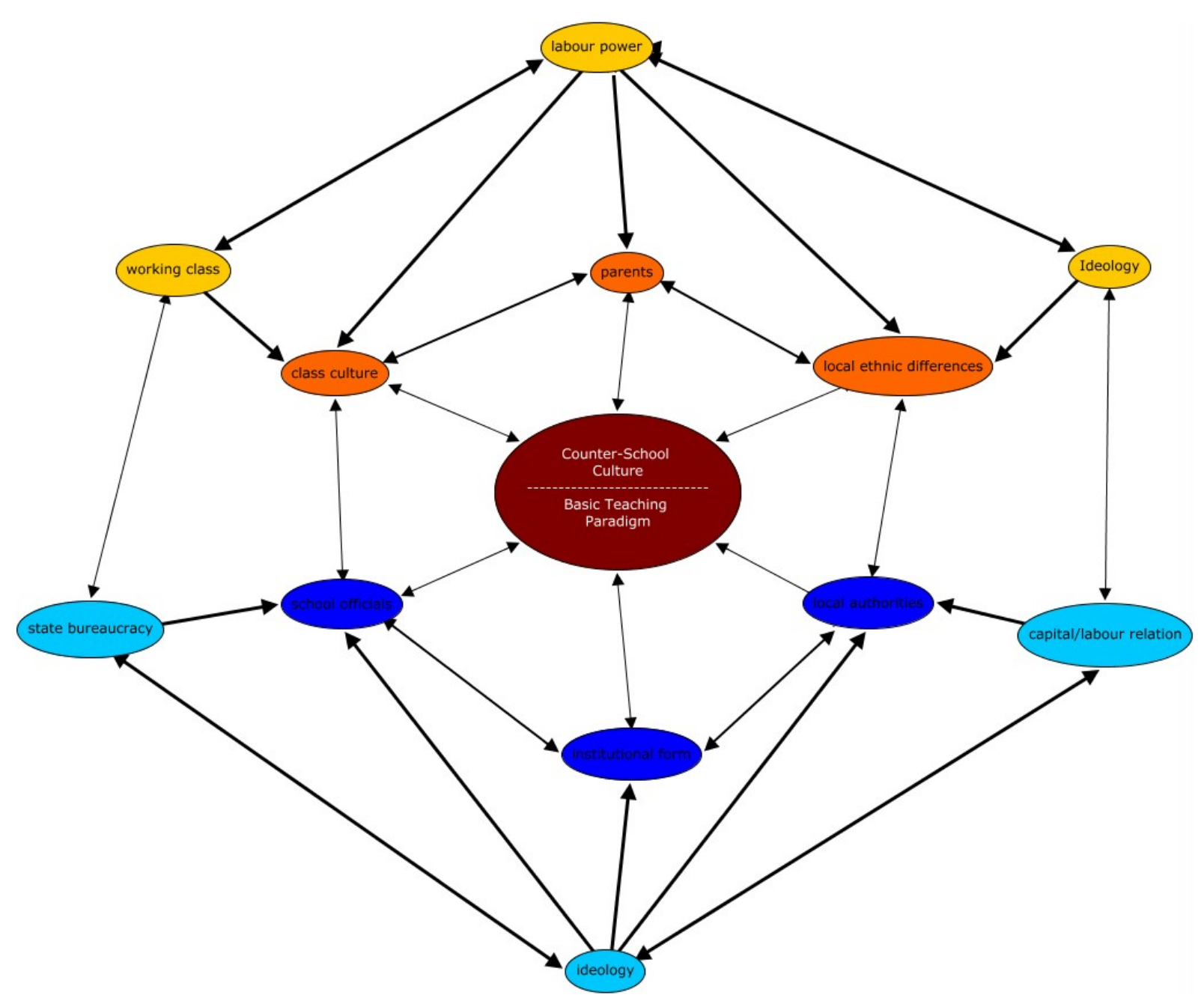




\section{Formato de citación}

Hadberg, Anders Vedel. (2006). The methodology of Paul Willis. A review of "Learning to Labor: How Working Class Kids get Working Class Jobs". Athenea Digital, 9. Disponible en http://antalya.uab.es/athenea/num9/hadberg.pdf.

Este texto está protegido por una licencia Creative Commons.
Usted es libre de copiar, distribuir y comunicar públicamente la obra bajo las
siguientes condiciones:
Reconocimiento: Debe reconocer y citar al autor original.
No comercial. No puede utilizar esta obra para fines comerciales.
Sin obras derivadas. No se puede alterar, transformar, o generar una obra
derivada a partir de esta obra.
$\underline{\text { Resumen de licencia }}$
Texto completo de la licencia

